\title{
Adaptability of SOA in loT Services - An Empirical Survey
}

\author{
Saravana Balaji B \\ Assistant Professor \\ College of Engg \& CS \\ Lebanese French University, \\ Iraq
}

\author{
Amin Salih Mohamed \\ Assistant Professor \\ College of Engg \& CS \\ Lebanese French University, \\ Iraq
}

\author{
Chiai Al-Atroshi \\ Lecturer \\ College of Engg \& CS \\ Lebanese French University, \\ Iraq
}

\begin{abstract}
Need for automation of industrial and domestic operations lead to the evolution of the Internet of Things. Internet of Things based services rely on sensors deployed over the monitoring area and provides information about the current status. Based on the information received different kind of services like decision making, alarming etc. provided. Service oriented architecture methodologies provided a platform for the development of advanced solutions like cloud computing, fog computing, software defined networking etc. In this paper an empirical survey is presented which deal with the issues and challenges of adapting service oriented architecture methodologies in IoT kind services. Also, a few novel methods that proposed by adopting SOA in IoT services discussed.
\end{abstract}

\section{General Terms}

Internet of Things, Service Oriented Architecture.

\section{Keywords}

SOA, IoT, Web Services, Model Driven, Distributed Events, Context Aware, Policy Aware.

\section{INTRODUCTION}

Internet of Things enables sensors deployed on a particular environment connected to the internet. From the internet an authorised user able to control the IoT devices. On the other hand, web services are the backbone of service oriented architecture which enables the development of social networking, b2b and b2c business models over the internet. Internet of things enables communication between people to people, people to objects and object to object which makes emerging of new types of services. Today's social networking era enables people to people communication through services like blogs, online games etc. [7]. By adopting IoT services, applications use objects like sensors to sense the status of the environment, exchange the information and use it for decision making. These services lead to the evolution of smart cities, emergency care, smart retail, industry management, smart agriculture, and many more domains. SOA based web services paradigm enabled automated service discovery and generation of new services by service composition techniques. The web services also support the dealing of data from different kind of sources. By adopting web services paradigm (SOA) into IoT services development and deployment, the complexity of integration of distributed and dynamic events, the process is minimised. Normally Internet of Things services is deployed in a larger environment with a lot of sensors. Due to this security, privacy, and openness are the major aspects that affect the IoT service operations. For an automation system to work efficiently, QoS factors like availability, reliability, management, interoperability, and robustness must be ensured [8]. Apart from those factors, an IoT service based system must be able to support extensibility, scalability, and interoperability among heterogeneous devices.

Meanwhile designing of IoT service architecture must consider the sensor physical characteristics, the ability to move geographically, communication techniques and standards. By designing so, these architectures support the integration of third party services which enables the operation focus on business process instead of underlying technology. This leads to low cost system maintenance and extension of the system when required is facilitated. The technical advancement of the SOA paradigm will help the IoT services to enable sustainability, reliability and heterogeneous service management. SOA methodologies based on various standards like REST, SOAP, WSDL etc. and IoT services are also having their standards like RFID, CoAP etc. [6]. Adopting SOA standards directly in the IoT scenario will lead to technical issues like compatibility etc. The next section provides various issues and challenges in adopting SOA methodologies in IoT service environment. Section III provides information about different IoT service methodologies which are developed by adopting SOA standards. Section IV provides future research directions in SOA - IoT merging. Section V concludes the paper.

\section{CHALLENGES AND ISSUES FOR IOT SERVICES IN ADAPTING SOA METHODOLOGIES}

The challenges for adapting SOA for an automation system is diverse in nature. The challenges can range from management to testing, to security issues. SOA adapted automation systems generates thousands of messages based on events across the distributed elements in many directions. Storing and responding according to these messages is a bigger challenge. If the automation systems accept the integration of third party applications from a different domain, then the messages types are different in nature and management of these messages is a complicated task. Providing security at appropriate levels of the application implementation is a challenging task under the successful implementation of SOA based services. It is a cumbersome task to provide different layer level security for the services that are integrating with other services. While SOA goals are to enhance IoT application interoperability primarily, its monolithic usage in recent IoT frameworks further amplifies the problem of scalability especially with the enormous number of predicted "things". IoT systems tend to expand, and with time, a capable SOA framework becomes too immovable to handle system extensibility. The issues exist in adapting SOA methodologies in IoT services are as given below. 
No standard format for the description of services: web services and SOA are having standards like WSDL, SOAP etc. But there is no standard format for description services is available for IoT based services. This has posed a great challenge in the issue of integration. Recent trends in context awareness and data management have applied the semantic web technologies of Ontology Web Language (OWL), but still, there exist no standard methods to describe IoT services both at the high and low semantic level [1].

Lack of context awareness based services: The context awareness is applied in SOA based services adequately. Current IoT systems suffer from insufficient context awareness of services due to inexpertly modeled semantics proliferating various unevenly distributed ontologies and incoherent semantics for services [2]

No standard service classification: In IoT based service implementation, device category used for cataloging the service offered in the environment. This type of practice attributes service to devices based on the unique identifier of both devices and services [3]. Meanwhile, there is no standard service classification is available as IoT services depend on devices where different device standards are in the market for device manufacturing. These services made discoverable if a request made to the service or device identifier

Complex data visualisation and analysis: IoT based services generally generate a large amount of data which needs big data processing techniques. As of now, current techniques are not emerged to support IoT based data processing effectively. The available standards provide little scope for tailored data collection and visualisation. Tailored data visualisation and analysis from an object's activities and environment can provide invaluable insight into the wellbeing and the continued adequacy of the system [4].

While developing solutions for the above issues, certain challenges need to address. The challenges are as given below.

Scalability The adaptability of IoT based services in many domains lead to the evolution of new kind of services. This will make the IoT based service discovery a cumbersome issue. The role of sensors as service providers, receiving stations, etc. are to be clearly defined. The integration of existing IoT services will become a challenge.

Heterogeneity New IoT standards need to be backward compatible and also must support heterogeneous service integration. This is feasible because of the availability of different service discovery protocols and IoT service datamodels that can be exploited towards subscribing, advertising and discovering services; Semantic heterogeneity, also become a challenge if different data models adapt different data representation techniques.

Mobility The IoT services mainly depend on wireless sensors. To explore the new opportunities of deploying IoT services in different domains, the service should support mobility. Developing standards for mobility based IoT services is a challenging task.

Security Any new emerging technology faces security issues as a great bottleneck for their adaptability in new domains. As IoT services based on sensors which run on battery power and minimum hardware is available, enforcing higher level security techniques is a challenging task. For any cost, security implementation cannot be compromised.
Fault Management IoT services are emerged to serve in a hazardous environment and in those cases, fault management is a difficult task. For example, enhancing the life time of service by enforcing new techniques for sensor awake and sleep switching is difficult in challenging environments.

\section{SOA - IOT COLLABORATIVE SYSTEMS}

Given adapting SOA methodologies in IoT implementation, vast research is in progress in academia and industry, and few methods have proposed. The proposed solutions discussed below

\subsection{Model Driven Development of SO-IoT Applications}

This system proposed by Claudia et al. [5]. This methodology supports the development of Service oriented Internet of Things applications based on model driven development approach. The proposed method uses four phases for development of SOA based IoT applications: 1) analysis of business requirements, 2) definition of the business logic, 3) design of the integrated services solution and 4) generation of the technological solution. By using semi-automatic and automatic transformation of business models, this approach reduces the development time and expenditures towards software development

\subsection{SOA based intelligent decision making in IoT services}

The system proposed by Alfonso et al. [9] is COLLECT: COLLaborativE ConText-aware Service Oriented Architecture for Intelligent Decision-Making in the Internet of Things. By developing a light message broker, the proposed system facilitates the integration of heterogeneous service domain context data. It also developed an enterprise service bus for effective delivery of data to several agents and their collaborative participation in the service. This system comprises the following components: enterprise service bus, context broker, CEP engine, data suppliers and complex events topic based broker. The service flows implemented in this system are: pattern deployment in the CFP engine, domain specific data reception, contextual data reception, complex event detection and submission to the message broker.

\subsection{Policy aware SOA for M-M communication}

The system proposed by Georglos et al. [10] is Secure Machine-to-Machine Service-Oriented Architecture (SeMMA). This system comprises four domains: M2M device domain, M2M network domain, M2M application domain, M2M service domain. The proposed M2M domains empower policy management, and thus enables business logic decision making. The service domain is responsible for the analysis of events and the development of applicable business rules. The details regarding the published IoT services and their associated service properties combined with the relevant business documents are maintained by the service registry. The proposed architecture developed a policy manager through which the enforcement of policies using an SOA based policy regulation taken place. Due to this policy enforcement, the security threats to event based M2M communication minimised. 


\subsection{Engineering Web Services for IoT}

In [11] Evelina et al. proposed a method for developing web services for the Internet of Things domain. The authors proposed a high level design approach for RESTful web services interfaces for trust and configuration management, and fault and security management. The proposed methodology studied over mobile monitoring paradigm, and it involves the following phases: Mobile Agent registration, configuration management, reporting of measurements data, fault and performance management.

\subsection{SOA based IoT Service Platform}

In [12] Yang et al. proposed a distributed event-based IoT service platform aims to enable the IoT domain services creation and minimise the complexity of service accessibility. The authors adopted service-oriented principles for the design and development of middleware for publish/subscribe operations. The IoT service message communication operations based on the SOAP protocol. This network operations enables the delivering of service invocations and also supports service endpoint addressing for service routing. The developed EDSOA platform consists of three parts: a distributed resource pool, a DEBS-based service environment, and a flexible service process utility. IoT resource models are the background adopted for the development of distributed resource pool. The IoT services registration done through resource register interfaces, and service discovery operations are through lookup interfaces. The proposed DEBS based environment allows resource updating service subscribes to data update events. The events from sensors are collected and pushed towards the subscribing services by the publish/subscribe service bus. Based on the events received, the new resource attributes that are received is used to revive the resource instances by the updating service and replaces the old instances in the resource pool.

\section{EMPIRICAL COMPARISON}

The above discussed methodologies are compared based on the tools used, techniques adapted and other factors which given in the table below.

Table 1: Empirical Comparison

\begin{tabular}{|c|c|c|c|c|c|}
\hline S.No & IoT System & $\begin{array}{c}\text { Development } \\
\text { Model }\end{array}$ & Phases & Test Case Used & $\begin{array}{l}\text { Concepts and } \\
\text { Players }\end{array}$ \\
\hline \multirow{4}{*}{1} & \multirow{4}{*}{$\begin{array}{l}\text { Model-Driven Development of } \\
\text { Service Oriented } \\
\text { IoT Applications }\end{array}$} & \multirow{4}{*}{ Model Driven } & $\begin{array}{c}\text { Business requirement } \\
\text { analysis }\end{array}$ & \multirow{4}{*}{ Smart Vehicle } & \multirow[t]{2}{*}{ Devices } \\
\hline & & & $\begin{array}{c}\text { Business logic } \\
\text { definition }\end{array}$ & & \\
\hline & & & $\begin{array}{c}\text { Integrated service } \\
\text { design }\end{array}$ & & \multirow{2}{*}{ Sensors } \\
\hline & & & $\begin{array}{c}\text { Technological solution } \\
\text { generation }\end{array}$ & & \\
\hline \multirow{5}{*}{2} & \multirow{5}{*}{$\begin{array}{c}\text { COLLECT: COLLaborativE } \\
\text { ConText-aware Service } \\
\text { Oriented } \\
\text { Architecture for Intelligent } \\
\text { Decision-Making in the Internet } \\
\text { of Things }\end{array}$} & \multirow{5}{*}{ Context Aware } & Enterprise service bus & \multirow{5}{*}{$\begin{array}{l}\text { Air Quality } \\
\text { (Air4Health) }\end{array}$} & Air quality \\
\hline & & & Context broker & & \multirow{2}{*}{ Hospital alerts } \\
\hline & & & CEP engine & & \\
\hline & & & Data suppliers & & \multirow[b]{2}{*}{ Global alert } \\
\hline & & & $\begin{array}{l}\text { Complex events topic } \\
\text { based message broker }\end{array}$ & & \\
\hline \multirow{4}{*}{3} & \multirow{4}{*}{$\begin{array}{l}\text { Policy-aware Service Oriented } \\
\text { Architecture for Secure } \\
\text { Machine-to-Machine } \\
\text { Communications }\end{array}$} & \multirow{4}{*}{ Policy Aware } & M2M device domain & \multirow{4}{*}{$\begin{array}{l}\text { Intelligent Bus on } \\
\text { Campus (iBuC) }\end{array}$} & \multirow[b]{2}{*}{ Control units } \\
\hline & & & M2M network domain & & \\
\hline & & & $\begin{array}{l}\text { M2M application } \\
\text { domain }\end{array}$ & & \multirow{2}{*}{$\begin{array}{l}\text { Estimated time of } \\
\text { arrival }\end{array}$} \\
\hline & & & M2M service domain & & \\
\hline \multirow{3}{*}{4} & \multirow{3}{*}{$\begin{array}{l}\text { Web Services for Internet of } \\
\text { Things Applications }\end{array}$} & \multirow{3}{*}{$\begin{array}{l}\text { RESTful Web } \\
\text { Services }\end{array}$} & $\begin{array}{l}\text { Mobile monitoring } \\
\text { core functions }\end{array}$ & \multirow{3}{*}{$\begin{array}{c}\text { Database Gateway } \\
\text { Utilization }\end{array}$} & \multirow{3}{*}{$\begin{array}{l}\text { Subscription } \\
\text { requests }\end{array}$} \\
\hline & & & & & \\
\hline & & & $\begin{array}{l}\text { Mobile monitoring } \\
\text { web service design }\end{array}$ & & \\
\hline
\end{tabular}




\begin{tabular}{|c|c|c|c|c|c|}
\hline & & & $\begin{array}{l}\text { Database access web } \\
\text { service design }\end{array}$ & & Guaranteed rate \\
\hline & & & $\begin{array}{l}\text { Web service } \\
\text { deployment }\end{array}$ & & Fixed peak rate \\
\hline \multirow{3}{*}{5} & \multirow{3}{*}{$\begin{array}{c}\text { Integrating Events into SOA for } \\
\text { IoT Services }\end{array}$} & \multirow{3}{*}{$\begin{array}{l}\text { Distributed } \\
\text { Event based }\end{array}$} & $\begin{array}{l}\text { Distributed resource } \\
\text { pool }\end{array}$ & \multirow{3}{*}{$\begin{array}{l}\text { Coalmine Monitor } \\
\text { Control System } \\
\text { (CMCS })\end{array}$} & $\begin{array}{l}\text { Coalmine } \\
\text { operations }\end{array}$ \\
\hline & & & $\begin{array}{l}\text { DEBS- service } \\
\text { environment }\end{array}$ & & Sensors \\
\hline & & & $\begin{array}{l}\text { Flexible service } \\
\text { process utility }\end{array}$ & & $\begin{array}{l}\text { Programmable } \\
\text { logic controller }\end{array}$ \\
\hline
\end{tabular}

\section{CONCLUSION}

By using the sensor, any electronic objects can have an internet connection at any time and environment which is called the Internet of Things. Internet of Things is nowadays adopting web services terminology in implementation which makes the devices as smart devices and also accepting external services for providing new services. The construction of the IoT service eco system is a challenging task as web services integration needs many standards. In service oriented architecture paradigm business logic is divided into smaller and independent programmable units. These units are distributed in nature and collaborate with each other to achieve business logic. The advantage of adopting SOA in the Internet of Things services is it makes the services agile in nature thus responding to varying business requirements from time to time. There has been much notable research carried out in adapting SOA in IoT services development. This paper presented an empirical survey on few IoT systems developed using SOA methodologies and analysed them under various factors.

\section{REFERENCES}

[1] Patrick Guillemin, F Berens, O Vermesan, P Friess, M Carugi, G Percivall, "Internet of Things: position paper on standardization for IoT technologies", 2015, Available at http://www.internet-of-thingsresearch.eu/pdf/IERC_Position_Paper_IoT_Standardizati on_Final.pdf

[2] Ovidiu Vermesan, Peter Friess, Patrick Guillemin, Sergio Gusmeroli, Harald Sundmaeker, Alessandro Bassi, Ignacio Soler Jubert, Margaretha Mazura, Mark Harrison, Markus Eisenhauer et al. (2011): Internet of things strategic research roadmap, pp. 9-52. 1, Rivers Publishers Aalborg

[3] Guangyi Xiao, Jingzhi Guo, Li Da Xu \& Zhiguo Gong, "User Interoperability with Heterogeneous IoT Devices through Transformation", IEEE Transactions on Industrial Informatics, Volume 10, Issue 2, May 2014, pp. 1486-1496.

[4] Giacomo Ghidini, Vipul Gupta, Sajal K Das, "SNViz: Analysis-oriented Visualization for the Internet of Things", 2010, Available at https://pdfs.semanticscholar.org/93cf/ 3aca8cdfc8f48c4ad595d886079a5b72bd45.pdf

[5] Claudia M. Sosa-Reyna, Edgar Tello-Leal, David LaraAlabazares, "Methodology for the model-driven development of service oriented IoT applications", Journal of Systems Architecture, Volume 90, 2018, pp. 15-22.

[6] Sarra Hammoudi, Zibouda Aliouat, and Saad Harous. 2018. Challenges and research directions for Internet of Things. Telecommun. Syst. Volume 67, No 2, February 2018, pp.367-385.

[7] Wei Wang, Kevin Lee, David Murray, “A global generic architecture for the future Internet of Things", Service Oriented Computing and Applications, Volume 11, Issue 3, pp.329-344.

[8] Ling Li, Shancang Li, Shanshan Zhao, "QoS-Aware Scheduling of Services-Oriented Internet of Things," IEEE Transactions on Industrial Informatics, vol. 10, no. 2, May 2014, pp. 1497-1505.

[9] Alfonso Garcia-de-Prado, Guadalupe Ortiz, Juan Boubeta-Puig, "COLLECT: COLLaborativE ConTextaware service oriented architecture for intelligent decision-making in the Internet of Things", Expert Systems with Applications, Volume 85, November 2017, pp. 231-248.

[10] Georgios Katsikogiannis, Dimitrios Kallergis, Zacharenia Garofalaki, Sarandis Mitropoulos, Christos Douligeris, "A policy-aware Service Oriented Architecture for secure machine-to-machine communications", Ad Hoc Networks, Volume 80, November 2018, pp. 70-80.

[11] Evelina Pencheva, Ivaylo Atanasov, "Engineering of web services for internet of things applications", Information System Frontiers, Volume 18, Issue 2, -April 2016, pp. 277-292.

[12] Yang Zhang, Jun-Liang Chen, Bo Cheng, "Integrating Events into SOA for IoT Services," IEEE Communications Magazine, vol. 55, no. 9, November 2017, pp. 180-186. 